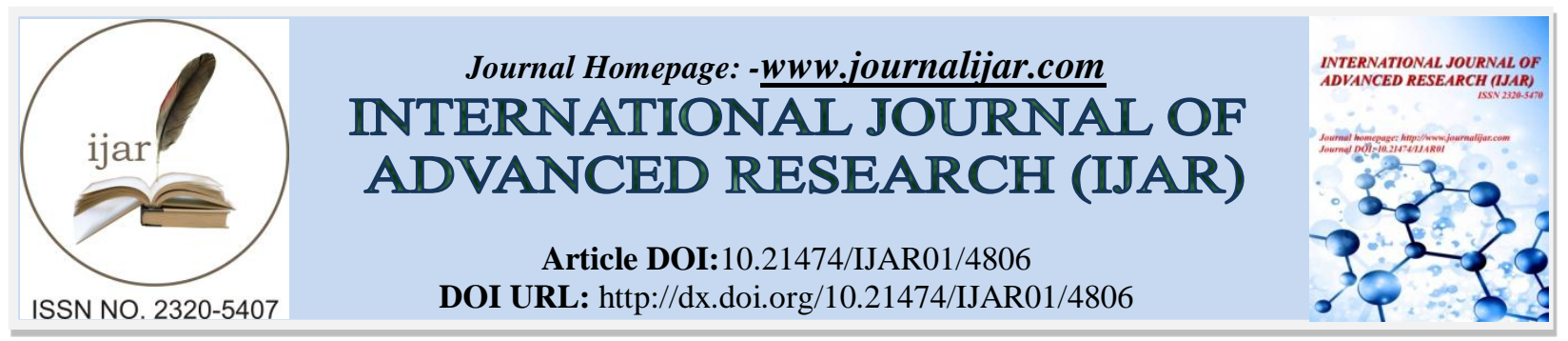

RESEARCH ARTICLE

\title{
ANALYSIS OF COMMONLY USED BLUE BALLPOINT PEN INK IN INDIA BY PLANAR CHROMATOGRAPHY.
}

\author{
Kiran. \\ M.sc Forensic Science, Amity Institute Of Forensic Sciences, Amity University, Noida.
}

\section{Manuscript Info}

Manuscript History

Received: 10 May 2017

Final Accepted: 12 June 2017

Key words:-

Thin layer chromatography; ink analysis, paper chromatography, blue ballpoint pen ink.
Published: July 2017

\begin{abstract}
Document examination has always been an important part of forensic examination. Incidents of forgery have increased tremendously and to alter these documents pens are widely used. Additions, alterations, obliterations play an important role in document examination. During a forensic document examination a major question which arises in the mind of examiner is: when was a particular ink entry made on the document? Immense numbers of documents are written, printed and copied each year and so are the suspect documents. Identification of suspected documents has become common subject for forensic document examination. Five brands of blue ballpoint pen which are widely used in India were taken (Two models from each brand). Ink entries were prepared by writing 'INK' word on paper. The analysis of writing ink (Blue ball point pen ink) by planar chromatography was done using paper chromatography and thin layer chromatography.

This study is aimed to determine the separation of ink within brands of blue ballpoint pen and results were compared with the acquired reference sample. The blue ballpoint ink is separated in order to find out the composition of ink and its separation within their brands, model and batches and also to find out that which technique of chromatography is best and also to find out which solvent system is best to perform ink analysis. Blue ink was not separated by paper chromatography but it was separated and differentiated by thin layer chromatography. Although both techniques are destructive in nature but Thin Layer Chromatography is best and reliable technique than paper chromatography.
\end{abstract}

Copy Right, IJAR, 2017,. All rights reserved.

\section{Introduction:-}

Immense numbers of documents are written, printed or typed each year so it has become an important part of document examination. Despite the advances in electronic transfer of documents, writing with some form of writing instrument such as pen, pencil, or marker is still popular. A signature entry made on a document which could be bill, cheque or bond is used to prove or confirm the identity of the person. Sometimes the authenticity of such documents comes into question and may require additional analysis to assess the claims. Since documents are integral part of our lives, it becomes easy to generate fraudulent documents by tampering or obliterating them. Ink is used to write or print any document so analysis of ink becomes an important part of forensic document examination. A document can be any material containing marks, symbols or signs that conveys meaning or message to anybody. Majority of 
documents are written on paper by typewriter or by hand with pencil or pen and ink, many other substances can be used for this purpose. A questioned document or disputed document belongs to category of these documents but it is suspected of being fraudulent or whose identity is suspected or source is unknown. Not all questioned documents are fraudulent. Sometimes documents are questioned in order to establish the identity of author or their source. Nowadays most commonly encountered inks on documents are writing inks and printing inks. Ballpoint pen inks are the most widely distributed of the commercially available pen inks. They contain synthetic dyes and glycol based solvents. Ballpoint pen ink contains $50 \%$ dye. Common dyes used to make blue ink are copper phthalocyanine blue, crystal violet, substituted triphenylmethane dyes. Crystal violet is a triarylmethane dye.

TLC is a standard ink analysis technique used in a significant number of published ink analysis methods, since the equipment is inexpensive compared to the cost of other instruments and also requires little training.

Hu-Sheng Chen [1] found that thin layer chromatography is a well-known technique for comparison of ink. It plays an important role in the routine examination of inks, although a great deal of research and development work is being done to develop more sophisticated and sensitive instruments for ink analysis. George $\mathrm{R}$ Nakamura [2] examined blue ink samples from popular American and Japanese ball point pens which were selected randomly and revealed that the dye formulation used in the manufacture of ball pen ink is not too diverse. TLC and spot test method confirmed that dyes such as methyl violet, rhodamine-B, Victoria blue, phalocyanine blue, and alkali blue were commonly used. Wilson D. J. [3] in his work differentiated the black gel inks using optical and chemical techniques. These techniques included microscopy, visible and near infrared reflectance, near infrared luminescence, thin-layer chromatography, spot test and gas chromatography-mass spectrometry and developed a flow chart for the determination of questioned ink samples. Volatile compounds present in the gel ink were analysed and it was found that there are some unique ingredients that can be found only in gel inks and cannot be found in other non-ballpoint inks. Marcin Kunicki [4] found that in destructive methods thin layer chromatography is the best method for differentiating blue ballpoint pen inks while in non- destructive methods best results were obtained by measurement of luminescence in visible and infrared light.

\section{Materials and Methods:-}

\section{Chemical and Reagents:-}

The chemicals used throughout the experiments were methanol, ethanol and ethyl acetate, distilled water, propan-2ol produced by Fisher Scientific (UK). The TLC silica gel plate 60 with layer thickness $0.25 \mathrm{~mm}$ and $20 \mathrm{X} 20 \mathrm{~cm}$ aluminium cards (Merck, Germany).

\section{Samples:-}

A set of blue ballpoint pen consists of 10 varieties were purchased from markets in Delhi/NCR. All pens were allocated a reference number during this study, as shown by Table 1. Four different individual pens were sampled for each of the pen variety. Experimental work was carried out on inks extracted from ink entries produced on white photocopier paper.

Table 1:-Reference number of pen samples taken for ink analysis.

\begin{tabular}{|l|l|l|}
\hline Brand Name & Model/batch & Reference No \\
\hline Flair & Writometer & A1 \\
& Ezee-click & A2 \\
\hline Nello & Zipper & B1 \\
& Maxriter & B2 \\
\hline Linc & All spark & C1 \\
& Palette & C2 \\
\hline Montex & Powerflow & D1 \\
& Combi & D2 \\
\hline
\end{tabular}




\section{Sample Preparation:-}

Each of the pens was used to write "INK" on a piece of white paper. After ink deposited on a paper, the absorbed ink was extracted from the ink entry of about $1 \mathrm{~cm} \mathrm{X} 1 \mathrm{~cm}$ with $0.5 \mathrm{ml}$ of methanol in a watch glass. A blank sample was prepared by treating a blank white paper with methanol.

\section{Solubility Test:-}

Solubility test was carried out in order to determine the solubility of writing ink in different solvents like methanol, ethanol, water, benzene, xylene, acetone, acetic acid, chloroform, ethyl acetate, pyridine, and n-hexane.

\section{Paper chromatography:-}

Writing ink was extracted using methanol.

Stationary Phase: A standard whatmann ${ }^{\circledR}$ cellulose filter paper (Merck ${ }^{\mathrm{TM}}$ Germany) was used, prepared by cutting to the desired dimensions.

Mobile phase: Ethanol (10 ml), Propan-2-ol (10 ml)

Spraying Reagent: No spraying reagent was used. Visualization was done in normal day light.

\section{Thin layer chromatography:-}

Writing ink was extracted using methanol.

Stationary Phase: A standard precoated TLC plate of Merck ${ }^{\mathrm{TM}}$ Germany having a thickness of $0.25 \mathrm{~mm}, \quad$ TLC was performed on silica gel doped aluminum plate (TLC Silica gel 60G F254, Merck), prepared by cutting to the desired dimensions.

Mobile phase: Ethyl acetate: Ethanol: Water (14: 6: $7 \mathrm{v} / \mathrm{v})$, n- Butanol: Ethanol: Water (10: 2: $3 \mathrm{v} / \mathrm{v})$ Spraying Reagent: No spraying reagent was used. Visualization was done in normal day light.

\section{Results:-}

Table 2:-solubility test of writing ink ( $+=$ 'Soluble', - = 'Not soluble')

\begin{tabular}{|l|l|l|l|l|l|l|l|l|l|l|}
\hline Samples & Water & Methanol & Ethanol & $\begin{array}{l}\text { Ethyl } \\
\text { acetate }\end{array}$ & Benzene & Chloroform & $\begin{array}{l}\text { n- } \\
\text { Hexane }\end{array}$ & Xylene & $\begin{array}{l}\text { Acetic } \\
\text { Acid }\end{array}$ & Acetone \\
\hline A1 & + & + & + & + & - & + & - & - & + & + \\
\hline A2 & + & + & + & + & - & + & - & - & + & + \\
\hline B1 & + & + & + & + & - & + & - & - & + & + \\
\hline B2 & + & + & + & + & - & + & - & - & + & + \\
\hline C1 & + & + & + & + & - & + & - & - & + & + \\
\hline C2 & + & + & + & + & - & + & - & - & + & + \\
\hline D1 & + & + & + & + & - & + & - & - & + & + \\
\hline D2 & + & + & + & + & - & + & - & - & + & + \\
\hline E1 & + & + & + & + & - & + & - & - & + & + \\
\hline E2 & + & + & + & + & - & + & - & - & + & + \\
\hline
\end{tabular}

Paper Chromatography:-

Paper chromatography of blue ballpoint pen ink using different solvent systems. 
Fig 1:-Paper chromatography of blue ink using solvent system Ethanol. No spots were detected.
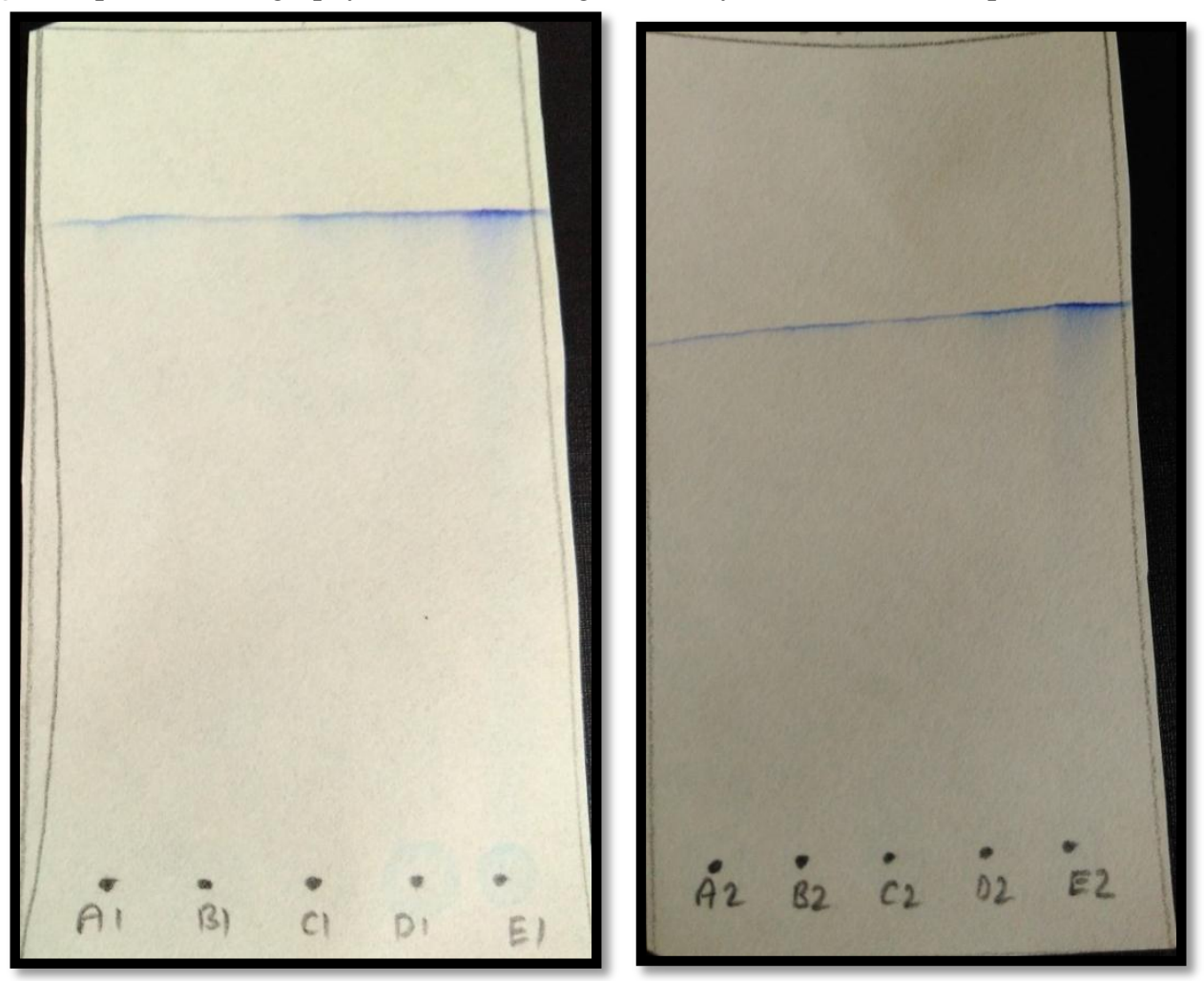

Fig 2:-Paper chromatography of blue ink using solvent system Propan-2-ol. No spots were detected.
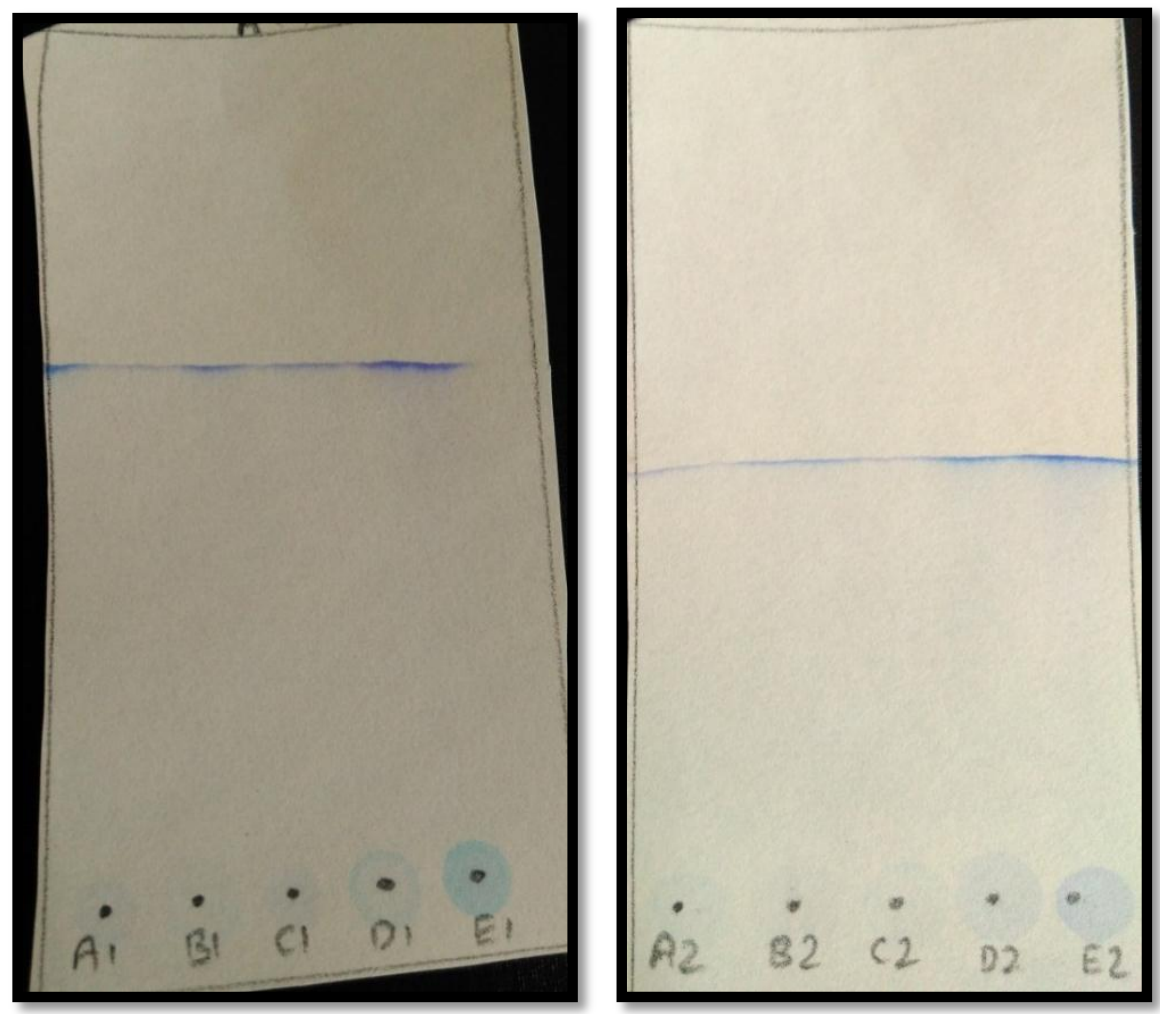


\section{Thin layer Chromatography:-}

Thin layer chromatography of blue ballpoint pen ink using different solvent systems.

Fig 3:-TLC of blue ink samples using solvent system Ethyl acetate: Ethanol: Water (14:6:7 v/v). Visualization was done in normal day light.

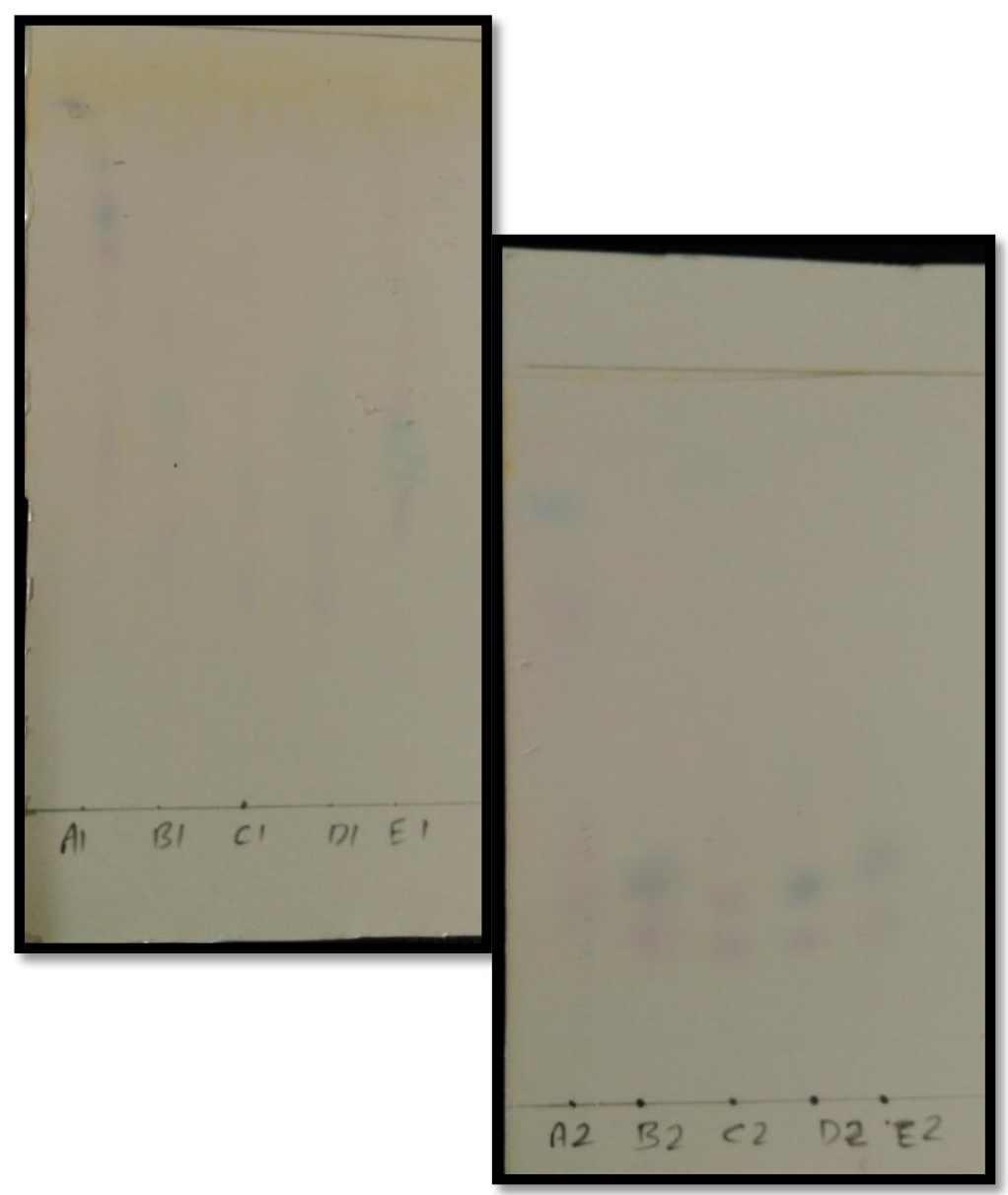


Fig 4:-TLC of Blue ink using solvent system n-Butanol: Ethanol: water (10:2:3 v/v). Visualization was done in normal day light.
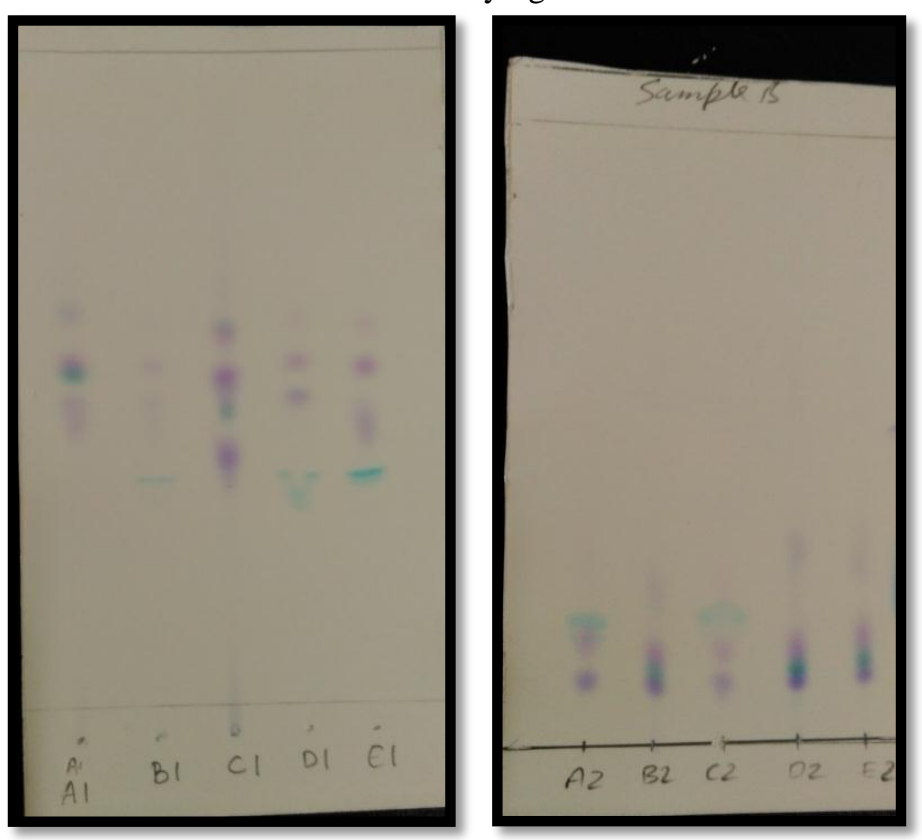

TLC of acquired reference sample using various solvent system

Fig 5:-TLC of acquired reference sample using solvent system. (A) Ethyl Acetate: Ethanol: water (B) n-Butanol: ethanol: water.

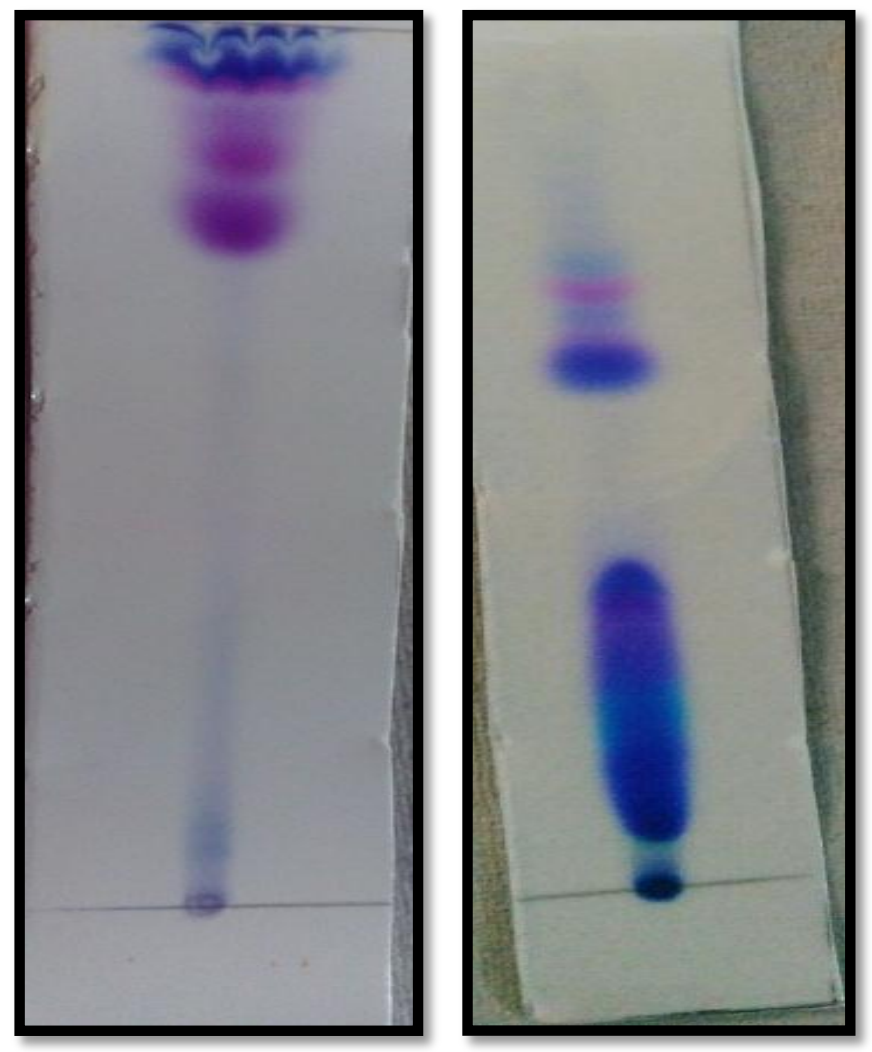




\section{Discussion:-}

Ink analysis is an important part of document examination. Ink can be examined by different types of methods. In this study, paper chromatography and thin layer chromatography was done to study the distribution of blue ballpoint pen ink. Five common pen brands Cello, Natraj, Linc, Flair and Montex were taken which are commonly used pen brands in India. Two blue ball pointed pen were taken from each brand. Reynolds blue ballpoint pen was taken as acquired reference sample. Solubility test was conducted to study and examine the solubility of blue ballpoint pen in different types of solvents. Blue ballpoint ink was found to be soluble in polar solvent rather than non-polar solvent. Ink was extracted from samples using methanol for the purpose of spotting. Paper chromatography was done by using two solvent system, first was ethanol and second solvent system was Propan-2-ol. Thin layer chromatography was done by taking two solvent systems. First solvent system was ethyl acetate: ethanol: water (14:7:6 v/v). Second solvent system was n-Butanol: ethanol: water (10:2:3 v/v). In solvent system I separation of ink was fairly moderate while in second solvent system wide separation of ink can be seen. Thus, the Second solvent system is best for analysis of blue ballpoint pen ink. The colour of spots were found to be blue and purple, where purple spot was due to presence of crystal violet dye and blue colour was due to presence of copper phthalocyanine blue dye, after compared with the acquired reference sample. The result of TLC (using solvent system I) showed that blue ink sample (A1, A2, B1, B2, C1, C2, D1, D2) are of similar composition but blue ink sample E1, E2 are of different composition. The results of TLC (Using solvent system II) showed that blue inks sample A1 and A2 are of similar composition, blue inks sample B1 and B2 are of different composition, blue ink sample $\mathrm{C} 1$ and $\mathrm{C} 2$ are of different composition, blue ink sample D1 and D2 are of different composition and blue ink sample E1 and E2 are of different composition.

\section{Conclusion:-}

Analysis of writing ink was examined by planar chromatography. All blue ball point pen ink (10 samples) was examined by solubility test, paper chromatography and thin layer chromatography. Blue ballpoint ink was found to be insoluble in nonpolar solvents while soluble in polar solvents. So, it can be said that all 10 (ten) samples of blue ballpoint pen ink are polar in nature. The separation of blue ink sample in paper chromatography was not good, and no spots were detected, but spots were detected in thin layer chromatography which separated blue ink in different spots. Based on the obtained results, we can say that thin layer chromatography is a better method for ink analysis than paper chromatography. Separation of blue ballpoint pen ink was found to be more in solvent system II as compared to solvent system I. It was found that concentration of crystal violet dye was more in comparison of copper phthalocyanine blue dye in all the 10 (ten) Samples. The major dyes were found to be crystal violet and copper phthalocyanine blue dye in all 10 samples after comparison with acquired reference sample. Hence, it can be said that all ten sample of blue ball point pen have different ink composition within their brands, model and batches to maintain the individuality and specificity of particular model.

\section{References:-}

1. Hu-Sheng Chen, $\mathrm{PhD}$, "A survey of methods used for the identification and Characterization of inks" Forensic Science Journal, 2002; 1:1-14.

2. George R. Nakamura, Satoru C. Shimoda, "Examination of Micro-Quantity of Ball Point Inks from Documents by Thin-Layer Chromatography” 56 J. Crim. L. Criminology \& Police Sci. 113 (1965).

3. J.D. Wilson, G.M. La Porte, A.A. Cantu, "Differentiation of black gel inks using optical and chemical techniques “, J. Forensic Sci. 49 (2004) 1-7.

4. Marcin Kunicki, "Differentiating blue ballpoint pen inks”, Z Zagadnieñ Nauk S1dowych, z. LI, 2002, 56-70.

5. Wilmer Souder, "Composition, Properties and Behavior of Ball Pens and Inks", 45 J. Crim. L. Criminology \& Police Sci. 743(1954-1955).

6. J. Martín-Gil, "chemical composition of a fountain ink pen” Journal of chemical education • October 2006.

7. Djozan djavanshir, "Forensic discrimination of blue ballpoint pen inks based on thin layer chromatography and image analysis", Forensic science international 179(2-3):199-205 - August 2008.

8. Loong Chuen Lee, Seow Lay Ying, Wan Nur Syazwani Wan Mohamad Fuad, Fast and Simple Forensic Red Pen Ink Analysis Using Ultra Performance Liquid Chromatography (UPLC), Malaysian Journal of Analytical Sciences, Vol 20 No 2 (2016): 224 - 230.

9. Janina Zie cba-Palus, Marcin Kunicki, Application of the micro-FTIR spectroscopy, Raman spectroscopy and XRF method examination of inks, Forensic Science International · June 2006.

10. Loong Chuen Lee, "The Analysis of Dyes in Black Ballpoint Pen Inks using High Performance Thin Layer Chromatography", and Malaysian Journal of Forensic Sciences (2014) 5(2):22-26.

11. Humecki, H. (1985). Experiments in ballpoint ink aging using infrared spectroscopy, in Proceedings of the 
International Symposium on Questioned Documents, FBI Academy, Quantico, VA, U.S. Government Printing Office, Washington, DC, pp. 131-135.

12. Dalwadi, D.H., Canet, C., Roye, N. \&Hedman, K.(2005). Rheology: an important tool in ink development, American Laboratory November, 18-22.

13. Cantu, A.A. \&Prough, R.S. (1987). "On the relative aging of ink - the solvent extraction technique", Journal of Forensic Sciences 32, 1151-1174.

14. Aginsky, V.N. (1993). Some new ideas for dating ballpoint inks - a feasibility study, Journal of Forensic Sciences 38, 1134-1150.

15. Aginsky, V.N. (1996). Dating and characterizing writing, stamp pad and jet printer inks by gas chromatography/mass spectrometry, International Journal of Forensic Document Examiners 2, $103-116$.

16. Weyermann, C., Marquis, R., Mazzella, W. \&Spengler,B. (2007). Differentiation of blue ballpoint pen inks by laser desorption ionization mass spectrometry and high-performance thin-layer chromatography, Journal of Forensic Sciences 52, 216-220.

17. Weyermann, C., Marquis, R., Mazzella, W. \&Spengler,B. (2007). Differentiation of blue ballpoint pen inks by laser desorption ionization mass spectrometry and high-performance thin-layer chromatography, Journal of Forensic Sciences 52, 216-220.

18. Lauren, M.P., A.W. Trevor, and W.R. Fawcett, High-Performance Liquid Chromatography; Ultraviolet; Visible Spectroscopy; Electrospray Ionization Mass Spectrometry Method for Acrylic and Polyester Forensic Fiber Dye Analysis. Journal of Forensic Sciences, 2006. 51(4): p. 771-779.

19. Denman, S., et al., "Photostability of Crystal Violet (CI 42555). Dyes and Pigments “, 1996. $30(1)$ : p. 67-72.

20. Egan, J.M., K.A. Hagan, and J.D. Brewer, Forensic analysis of black ballpoint pen inks using capillary electrophoresis. Forensic Science Communications, 2005. 7(3).

21. Ng, L.K., P. Lafontaine, and L. Brazeau, "Ballpoint pen inks: characterization by positive and negative ionelectrospray ionization mass spectrometry for the forensic examination of writing inks Journal of Forensic Sciences, 2002. 47(6): p. 1238-1247.

22. CoLrwELL, B. B., "The Comparison of Inks and Writings by Paper Chromatography". THE ANALYST, 80,68 (1955).

23. Aginsky VN, "Comparative examination of inks by using instrumental thin-layer chromatography and microspectrophotometry". Journal of Forensic Sciences (1993), 38(5): 1111-1130.

24. Senior, S., Hamed, E., Masoud, M. \&Shehata, E. (2012). Characterization and dating of blue ballpoint pen inks using principal component analysis of UV-Vis absorption spectra, IR spectroscopy and HPTLC. Journal of Forensic Sciences 57:1087-1093.

25. Roux C., Novotny M., Evans I. [e t a 1.], A study to investigate the evidential value of blue and black ballpoint pen inks in Australia, Forensic Science International 1999, vol. 101, pp. 167-176.

26. Lauren, M.P., A.W. Trevor, and W.R. Fawcett, High-Performance Liquid Chromatography; Ultraviolet; Visible Spectroscopy; Electrospray Ionization Mass Spectrometry Method for Acrylic and Polyester Forensic Fiber Dye Analysis. Journal of Forensic Sciences, 2006. 51(4): p. 771-779.

27. Denman, S., et al., "Photostability of Crystal Violet (CI 42555). Dyes and Pigments “, 1996. $30(1)$ : p. 67-72.

28. Egan, J.M., K.A. Hagan, and J.D. Brewer, Forensic analysis of black ballpoint pen inks using capillary electrophoresis. Forensic Science Communications, 2005. 7(3).

29. Ng, L.K., P. Lafontaine, and L. Brazeau, "Ballpoint pen inks: characterization by positive and negative ionelectrospray ionization mass spectrometry for the forensic examination of writing inks Journal of Forensic Sciences, 2002. 47(6): p. 1238-1247.

30. CoLrwELL, B. B., "The Comparison of Inks and Writings by Paper Chromatography". THE ANALYST, 80,68 (1955).

31. Aginsky VN, "Comparative examination of inks by using instrumental thin-layer chromatography and microspectrophotometry". Journal of Forensic Sciences (1993), 38(5): 1111-1130.

32. Senior, S., Hamed, E., Masoud, M. \&Shehata, E. (2012). Characterization and dating of blue ballpoint pen inks using principal component analysis of UV-Vis absorption spectra, IR spectroscopy and HPTLC. Journal of Forensic Sciences 57:1087-1093.

33. Roux C., Novotny M., Evans I. [e t a 1.], A study to investigate the evidential value of blue and black ballpoint pen inks in Australia, Forensic Science International 1999, vol. 101, pp. 167-176.

34. Merrill R. A., Ba r t i c k E. G., Analysis of ballpoint pen inks by diffuse reflectance infrared spectrometry, Journal of Forensic Sciences 1992, vol. 37, pp. 528-541.

35. Huang, M., J. Yinon, and M.E. Sigman, Forensic identification of dyes extracted from textile fibers by liquid chromatography mass spectrometry (LC-MS). Journal of Forensic Sciences, 2004. 49(2): p. 238-249. 